\title{
The national incidence of PML in Sweden, 1988-2013
}

Ellen lacobaeus, MD, PhD, Sarah Burkill, MSc, Shahram Bahmanyar, MD, PhD, Ramil Hakim, MD, Camilla Byström, Michael Fored, MD, PhD, Tomas Olsson, MD, PhD, Lou Brundin, MD, PhD,* and Scott Montgomery, BSc, PhD*

Neurology ${ }^{\circledR}$ 2018;90:e498-e506. doi:10.1212/WNL.0000000000004926

\begin{abstract}
Objective

To investigate the incidence of progressive multifocal leukoencephalopathy (PML) and patient characteristics in Sweden between 1988 and 2013.
\end{abstract}

\section{Methods}

All PML diagnoses in Sweden between 1988 and 2013 were identified in the National Patient Register. Information to validate the diagnosis and patient characteristics was obtained from medical records.

\section{Results}

Medical record review classified 108 out of 250 patients $(43 \%)$ as definite $(n=84)$, probable $(\mathrm{n}=4)$, or possible $(\mathrm{n}=20)$ PML according to diagnostic criteria. Accurate diagnoses were more common in records obtained from neurology departments $(82 \%$ of patients seen in neurology departments) compared with other departments $(31 \%)(p<0.001)$. The incidence of PML increased from a largely stable level at 0.026 (95\% confidence interval [CI] 0.021-0.031) per 100,000 individuals per year during 1988-2010 to 0.11 (95\% CI 083-0.137) during 2011-2013, during which time there was a notable increase $(p<0.001)$. Hematologic malignancies $(n=34), \operatorname{HIV} / \operatorname{AIDS}(\mathrm{n}=33)$, and autoimmune disease $(\mathrm{n}=23)$ were the most common underlying diseases. Treatment with a monoclonal antibody prior to PML diagnosis was identified in 26 patients.

\section{Conclusion}

An increased incidence of PML in Sweden was observed and coincided with the prior use of monoclonal antibody treatment. The high level of misdiagnosis emphasizes the importance of immediate contact with a neurology center upon suspicion of PML.

\author{
Correspondence \\ Dr. lacobaeus \\ Ellen.lacobaeus@ \\ karolinska.se
}

\section{- CME Course}

NPub.org/cmelist

\section{RELATED ARTICLE}

\section{Editorial}

Progressive multifocal leukoencephalopathy: Are you aware of it?

Page 255

\footnotetext{
*These authors contributed equally to this work.
}

From the Department of Clinical Neuroscience, Division of Neurology (E.L., R.H., T.O., L.B.), Neuroimmunology Unit, Center for Molecular Medicine, Department of Clinical Neuroscience (T.O., L.B.), and Center for Pharmacoepidemiology (S. Burkill, S. Bahmanyar, C.B.) and Clinical Epidemiology Unit (M.F., S.M.), Department of Medicine, Solna, Karolinska Institutet, Stockholm; Clinical Epidemiology and Biostatistics (S.M.), School of Medical Sciences, Örebro University, Sweden; and Department of Epidemiology and Public Health (S.M.), University College London, UK.

Go to Neurology.org/N for full disclosures. Funding information and disclosures deemed relevant by the authors, if any, are provided at the end of the article. 


\section{Glossary}

$\mathbf{C I}=$ confidence interval; HAART $=$ highly active antiretroviral therapy; $\mathbf{H R}=$ hazard ratio; $\mathbf{I C D}=$ International Classification of Diseases; IQR = interquartile range; JCV = JC virus; $\mathbf{M S}=$ multiple sclerosis; NSPR = National Swedish Patient Register; PML = progressive multifocal leukoencephalopathy; RA = rheumatoid arthritis; SLE = systemic lupus erythematosus.

Progressive multifocal leukoencephalopathy (PML) is a rare, often fatal disease of the CNS occurring predominantly in immunosuppressed individuals. ${ }^{1}$ It is caused by reactivation of latent JC virus (JCV) that lytically infects oligodendrocytes and astrocytes, causing widespread demyelinating lesions in the brain. ${ }^{1}$

There is no antiviral drug against PML and agents investigated for this purpose, including cidofovir, mirtazapine, mefloquine, and CCR5 antagonists, have not shown a convincing benefit for survival. ${ }^{2-5}$ Treatment strategies rather aim to restore host immune competence, which has been associated with improved outcomes. ${ }^{3}$

Historically, PML has been observed mainly in persons with hematologic malignancies. ${ }^{6}$ The HIV/AIDS pandemic resulted in a markedly increased PML incidence, which later declined with the use of highly active antiretroviral therapy (HAART) $)^{7,8}$ PML has also been reported rarely in patients with autoimmune diseases, solid tumors, and in organ transplant recipients. ${ }^{9}$ In recent years, an increasing frequency of PML has been noted among patients treated with new targeted immunoregulatory agents such as monoclonal antibodies. ${ }^{10,11}$ Despite their different effects on immune function, a number of biological medications were found to possibly confer an increased PML risk, regardless of the disease being treated. ${ }^{12,13}$ We conducted a descriptive study of PML in Sweden between 1988 and 2013, to investigate diagnostic accuracy, incidence, clinical characteristics, and survival. Few, if any, previous studies of PML have had a catchment area as well-defined as an entire country, with a study period as long as 25 years.

\section{Methods}

\section{Study population and measures}

Individuals with a record of a PML diagnosis (ICD-10 code A81.2, ICD-9 code 046D) in the National Swedish Patient Register (NSPR) between 1988 and 2013 were identified and the date of the first hospital admission for PML was used as the index date. ${ }^{14}$ The Swedish Cause of Death Register provided complementary information to identify patients with a diagnosis of PML. The unique Swedish personal identification number was used to identify patients across all sources of information. Permission was sought from all clinics where PML diagnoses were recorded, as identified through the register data, to obtain information from medical records. The records were first reviewed by a specialist in neurology (E.I.) and information was collected systematically including sex, age and year of diagnosis, symptoms at onset, results from neuroimaging, CSF JCV analyses, neuropathologic analyses, blood leukocyte count, comorbidities, immunosuppressive treatments 24 months prior to PML onset, outcome, and date of death.

Each patient was defined as having definite, probable, or possible PML or no PML using the criteria from the consensus statement published in $2013 .{ }^{15}$ To validate the accuracy of our diagnostic categorization, medical records for $10 \%$ of all definite/probable/possible/not PML diagnoses were reviewed independently for a second time by 2 other neurologists (T.O. and L.B.). Queries about the diagnosis were rare due to the strictness of the diagnostic criteria applied ${ }^{15}$ and only 2 diagnoses had to be discussed for a joint decision: the diagnostic category was not changed for any patient following discussion. Change in PML incidence during the study period (1988-2013) was assessed by dividing number of new diagnoses per year by the total Swedish population for each year (official statistics from Statistics Sweden; scb.se) and multiplied by 100,000 .

\section{Statistical analysis}

Incidence rate per 100,000 person-years was defined as the fraction of new PML diagnoses per calendar year among the general population in Sweden (1988-2013). Descriptive statistics were calculated for patient characteristics. Median (25th-75th percentile) and frequencies were used when appropriate. Continuous variables were compared using a 2-sided Wilcoxon rank-sum test. Time trends were estimated using local nonparametric regression models. Contingency tables were evaluated using the Fisher exact test.

Survival functions (for survival duration following diagnosis) were determined using the Kaplan-Meier approach. Differences between survival functions were analyzed using the log-rank test. A Cox proportional hazards model was implemented to adjust for potential confounding factors. The proportional hazards assumption was assessed using the Pearson product moment correlation coefficient ( $p$ values $<0.05$ were considered significant). The statistical analysis was performed in $\mathrm{R}$ (version 3.3.2) using packages tidyverse, data.table, survival, survminer, cowplot, and RColorBrewer.

\section{Results}

\section{Confirmation of the PML diagnosis}

We identified 281 patients with a diagnosis of PML using the Patient Register between 1988 and 2013. Medical records 
were available for 250 (89\%) patients covering 144 separate clinics. Review of the available medical records $(\mathrm{n}=250)$ indicated PML in 108/250 (43\%) of the diagnoses with 84 (34\%) definite PML, 4 (2\%) probable PML, and 20 (8\%) possible PML, using consensus statement criteria (table 1$).{ }^{15}$ Definite PML diagnoses were established based on typical clinical and radiographic presentation, in combination with JCV detection in CSF in 71/108 patients (66\%). Quantitative JCV CSF analyses, available in 42/108 patients (39\%), showed a viral load between 14 and 3.45 million JCV copies/ $\mathrm{mL}$ in the first test. Some 8 patients had a negative first test prior to a second positive test and one patient tested negative twice, prior to detection of JCV in the third CSF analysis. A positive JCV test established by qualitative methods was based on detection of $\geq 200$ copies of JCV DNA/mL in CSF.
Neuropathologic confirmation of JCV ascertained a definite or probable PML diagnosis in 21/108 patients (19\%). The definite/probable/possible PML diagnoses mainly originated from departments of neurology $(\mathrm{n}=41 ; 38 \%)$, infectious diseases $(\mathrm{n}=31 ; 29 \%)$, internal medicine $(\mathrm{n}=28 ; 25 \%)$, rheumatology $(n=3 ; 3 \%)$, oncology $(n=2 ; 2 \%)$, neurosurgery $(n=1 ; 1 \%)$, and psychiatry $(n=1 ; 1 \%)$.

An incorrect diagnosis of PML was found in 142 (57\%) patients (49\% women, median age 66 years). Revised diagnoses in the falsely diagnosed PML group are listed in table e-1 (links.lww.com/WNL/A117), none of these patients had a positive CSF JCV test. An accurate PML diagnosis was more common in neurology departments (correct; $\mathrm{n}=41 ; 82 \%$ ) compared with other departments (correct; $n=67 ; 31 \%$ ).

Table 1 Characteristics of patients with a definite/probable/possible progressive multifocal leukoencephalopathy (PML) diagnosis

\begin{tabular}{|c|c|c|c|c|c|c|}
\hline & Total & $\begin{array}{l}\text { Hematologic } \\
\text { malignancy }\end{array}$ & HIVIAIDS & $\begin{array}{l}\text { Autoimmune } \\
\text { diseases }\end{array}$ & $\begin{array}{l}\text { Solid tumor/organ transplant/ } \\
\text { primary immune disease }\end{array}$ & $\begin{array}{l}\text { Previously } \\
\text { healthy }\end{array}$ \\
\hline Patients, n (\%) & 108 & $34(31)$ & $33(31)$ & $23(21)$ & $11(10)$ & $7(6)$ \\
\hline Definite PML & 84 & 26 & 22 & 23 & 7 & 6 \\
\hline Probable PML & 4 & 2 & 2 & 0 & 0 & 0 \\
\hline Possible PML & 20 & 6 & 9 & 0 & 4 & 1 \\
\hline Sex, M/F & $63 / 45$ & $21 / 13$ & $25 / 8$ & $7 / 16$ & $9 / 2$ & $1 / 6$ \\
\hline Age at PML onset, $y$, median, (IQR) & $58(41-65)$ & $64(60-71)$ & $48(38-52)$ & $52(42-66)$ & $60(53-66)$ & $71(61-73)$ \\
\hline \multicolumn{7}{|l|}{ Year of PML diagnosis, $\mathbf{n}(\%)$} \\
\hline 1988-1992 & 14 & $5(36)$ & $6(43)$ & 0 & $3(21)$ & 0 \\
\hline 1993-1997 & 22 & $6(27)$ & $14(64)$ & $1(5)$ & 0 & $1(5)$ \\
\hline 1998-2002 & 13 & $4(31)$ & $5(38)$ & $2(15)$ & $2(15)$ & 0 \\
\hline 2003-2007 & 15 & $4(27)$ & $3(20)$ & $3(20)$ & $3(20)$ & $2(13)$ \\
\hline 2008-2013 & 44 & $15(34)$ & $5(11)$ & $17(39)$ & $3(7)$ & $4(9)$ \\
\hline CSF JCV DNA & 71 & 24 & 19 & 21 & 3 & 4 \\
\hline Neuropathologic evidence for JCV & 21 & 6 & 5 & 3 & 4 & 3 \\
\hline WBC, median $\times 10^{6} / \mathrm{mL}$ & 5.0 & 5.0 & 2.5 & 8.0 & 5.0 & 12.4 \\
\hline Immunosuppressive treatment ${ }^{\mathrm{b}}$ & 62 & 33 & 0 & 23 & 6 & 0 \\
\hline Monoclonal antibody & 26 & 15 & 0 & 11 & 0 & 0 \\
\hline
\end{tabular}

Anti-PML treatment, $\mathrm{n}(\%)$

\begin{tabular}{lllllll}
\hline Cytarabine & $19(18)$ & 7 & 5 & 3 & 3 & 1 \\
\hline Mirtazapine & $24(22)$ & 6 & 0 & 15 & 2 & 1 \\
\hline Mefloquine & $14(13)$ & 5 & 0 & 8 & 1 & $4(57)$ \\
\hline Mortality rate & $80(75)$ & $30(88)$ & $28(85)$ & $10(43)$ & $8(73)$ & $3(3-8)$
\end{tabular}

Abbreviations: IQR = interquartile range; JCV = JC virus; $W B C=$ white blood cell count at PML onset.

${ }^{a}$ Number of patients with positive JCV DNA in CSF.

${ }^{b}$ Number of patients treated with immunosuppressive therapy within the latest 12 months. 
With some variation, the accuracy of the PML diagnosis remained low for much of the study period, but with evidence of a more notable improvement from 2010 at a time when the diagnosis became more common (figure 1). When the years are grouped, $60 \%$ of diagnoses were accurate from 2008 and $68 \%$ from 2011. The inconsistent temporal pattern over the study period and the low number of observations after 2010 do not allow for reliable statistical analysis.

\section{Incidence}

The incidence of definite/probable/possible PML in Sweden increased from a stable average rate of 0.026 (95\% confidence interval [CI] 0.021-0.031) per 100,000 individuals per year between 1988 and 2010 to $0.11(0.083-0.137)$ per 100,000 individuals per year between 2011 and 2013 (figure 2A) ( $p<$ $0.001)$, when a notable increase in incidence was observed.

\section{Patient characteristics}

The characteristics of all patients with PML are described in table 1 . The autoimmune diagnoses included multiple sclerosis (MS) $(n=8 ; 7 \%)$, systemic lupus erythematosus (SLE) $(\mathrm{n}=4 ; 4 \%)$, rheumatoid arthritis (RA) $(\mathrm{n}=3 ; 3 \%)$, systemic sarcoidosis $(n=2 ; 2 \%)$, dermatomyositis $(n=2 ; 2 \%)$, Behçet disease $(n=1 ; 1 \%)$, polymyalgia rheumatica $(n=1 ; 1 \%)$, Goodpasture syndrome $(\mathrm{n}=1 ; 1 \%)$, and cryoglobulinemic vasculitis $(n=1 ; 1 \%)$. The absence of underlying morbidity associated with immunodeficiency or immunosuppressive medication was found in 7 patients. Bone marrow examination, with normal results, was performed in only 2 of these patients; hence an occult immunodeficiency could not be ruled out in the 5 other patients. However, medical record review did not indicate signs of immunodeficiency. A statistically significant change in proportions of underlying diseases in PML was detected during 1988-2013 ( $p<0.001$ ) (figure $2 \mathrm{~B}$, table 1). HIV/AIDS was associated with $43 \%$ of the PML diagnosed during the first fifth of the study period (1988-1992) compared with the last fifth (2008-2013), during which $11 \%$ of the patients had HIV/AIDS. Autoimmune diseases were found in $39 \%$ of all patients with PML in 2008-2013 compared with none during 1988-1992. The proportion of hematologic malignancies was relatively unchanged over time (36\% during 1988-1992 and 34\% during 2008-2013).

\section{Clinical and radiologic findings}

The median age at PML onset in the 108 patients with definite/probable/possible PML was 58 years (interquartile range $[\mathrm{IQR}] 41-65$ years $)$ and $58 \%(\mathrm{n}=63)$ of the patients were male (table 1). Clinical symptoms at PML onset are listed in table 2. Brain MRI $(n=86)$ and CT $(n=16)$ identified PML lesions in 97 (89\%) of the patients and infratentorial lesions in 27 (25\%) of the patients on their first examination (table 2$)$. The majority of patients $(n=81 ; 74 \%)$ presented with multilobular lesions and unilobular lesions were found in $22(20 \%)$ patients. Contrast enhancement was detected in 13 (12\%) patients. One of the patients with natalizumab-associated PML had a preclinical MRI PML lesion that was initially interpreted incorrectly as a new MS lesion. Interestingly, 1 (0.9\%) patient with cancer, receiving chemotherapy, presented with a PML lesion visible on MRI in the thoracic spinal cord in addition to PML lesions in the frontal lobes. The diagnosis in this patient was confirmed on an autopsy specimen of the brain and spinal cord.

\section{Immunosuppressive treatment prior to PML}

A total of 62 (57\%) patients with definite/probable/possible PML (HIV/AIDS excluded) had current or prior treatment (within the last 12 months) with immunosuppressants or chemotherapy (table 1). All treatments are listed in table e-2 (links.lww.com/WNL/A117). Treatment with biological

Figure 1 Proportion of correct progressive multifocal leukoencephalopathy (PML) diagnoses over time

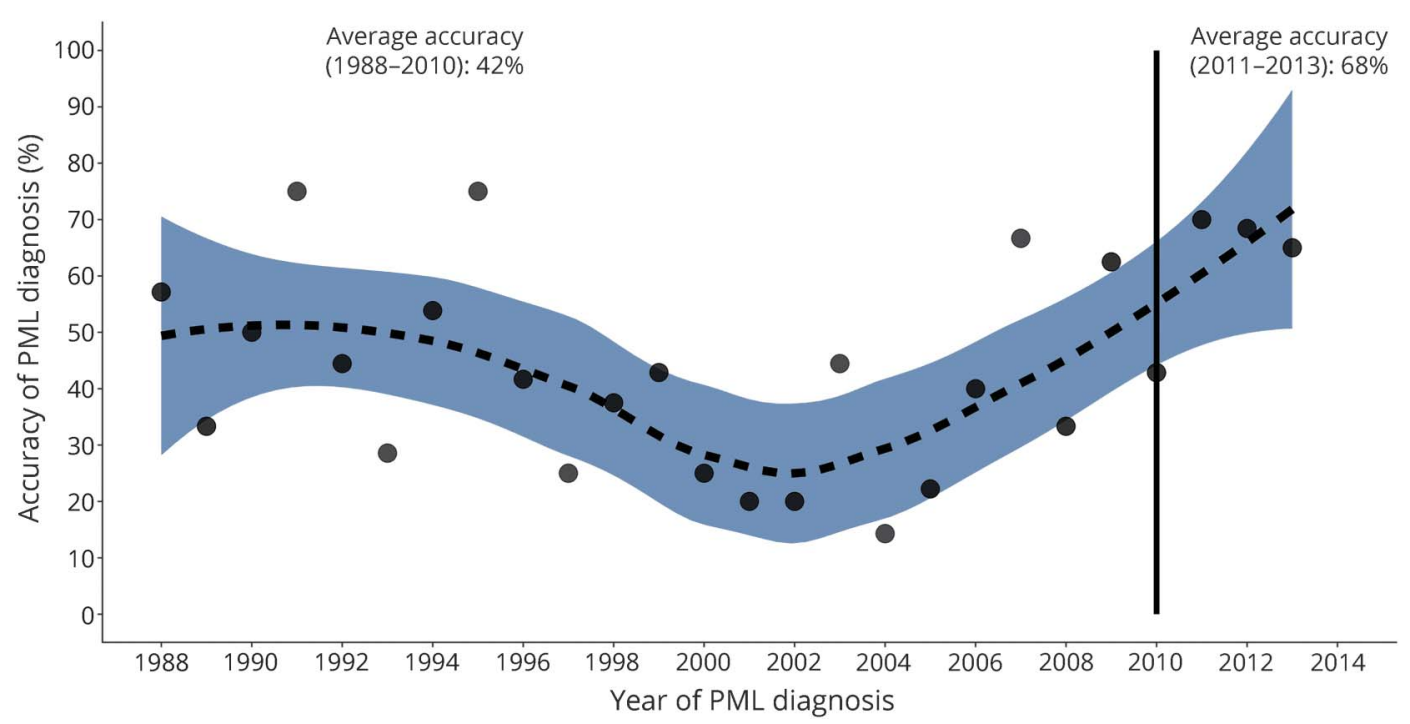




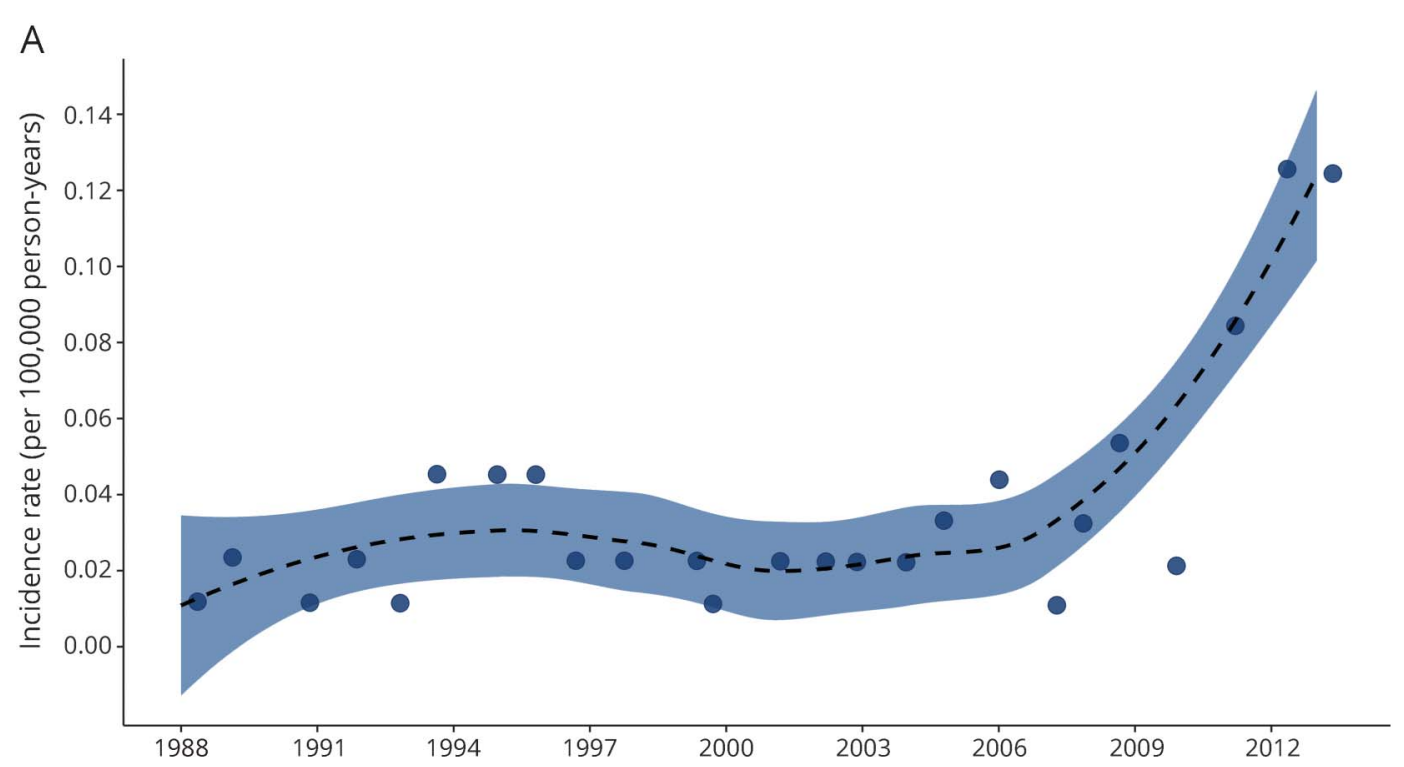

B

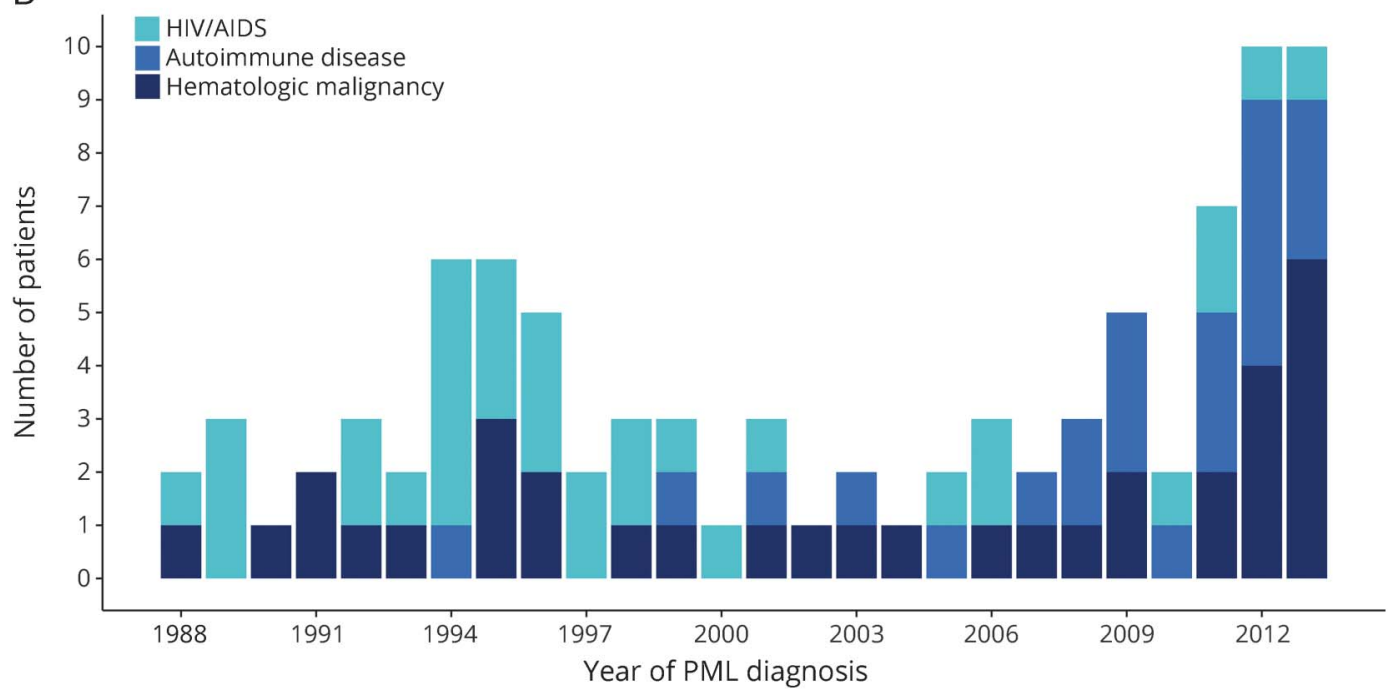

(A) The incidence rate of PML per 100,000 person-years in Sweden between 1988 and 2013: each point represents the annual rate; the trend line has 95\% confidence intervals (Cls). The incidence rate between 1988 and 2010 was estimated as 0.026 ( $95 \% \mathrm{Cl} 0.021-0.031)$ and $0.11(0.083-0.137)$ between 2011 and 2013. (B) The annual distribution of the 3 most common disease categories associated with PML: HIV/AIDS, autoimmune disease, and hematologic malignancy. Only patients with definite/probable/possible PML are included.

agents within 12 months prior to PML was detected in 26 patients (15 patients with hematologic malignancy and 11 with autoimmune disease) including rituximab $(\mathrm{n}=15)$, natalizumab $(\mathrm{n}=8)$, alemtuzumab $(\mathrm{n}=2)$, ofatumumab $(\mathrm{n}=1)$, and infliximab $(\mathrm{n}=1)$ and treatment duration was at least 6 months before PML onset. One patient with MS had received both natalizumab and rituximab. In all but 2 patients with hematologic malignancy, monoclonal antibody therapy was part of chemotherapy regimen (except 1 treated with alemtuzumab as monotherapy and 1 who received rituximab and prednisolone). The patients with autoimmune diseases (except MS) included 1 patient with SLE treated with rituximab and prednisolone and 1 patient with cryoglobulinemic vasculitis and 1 patient with RA who were both treated with methotrexate, prednisolone, and rituximab.

The majority of PML diagnoses associated with monoclonal antibody therapy occurred after $2006(\mathrm{n}=24)$ but 2 patients with hematologic malignancy, exposed to rituximab, developed PML in 2001 and 2002, respectively.

\section{Outcome}

After a follow-up time of 24 months, 80 (74\%) of the patients with definite/probable/possible PML had died (table 1). The median age at PML onset in patients with a fatal outcome $(\mathrm{n}=80)$ was 59.5 years (IQR 48-67), while 
Table 2 Clinical and neuroradiologic findings in definite/probable/possible progressive multifocal leukoencephalopathy (PML)

\begin{tabular}{|c|c|c|c|c|c|c|}
\hline & Total & AIDS/HIV & $\begin{array}{l}\text { Hematologic } \\
\text { malignancy }\end{array}$ & $\begin{array}{l}\text { Autoimmune } \\
\text { disease }\end{array}$ & $\begin{array}{l}\text { Solid tumor/organ } \\
\text { transplant/primary } \\
\text { immune disease }\end{array}$ & $\begin{array}{l}\text { Previously } \\
\text { healthy }\end{array}$ \\
\hline Patients & 108 & 33 & 34 & 23 & 11 & 7 \\
\hline \multicolumn{7}{|l|}{$\begin{array}{l}\text { Symptoms and signs on neurologic } \\
\text { examination at PML onset }\end{array}$} \\
\hline Motor weakness & $79(73)$ & $22(67)$ & $22(65)$ & $20(87)$ & $10(91)$ & $5(70)$ \\
\hline Speech difficulties (dysphasia or dysarthria) & $55(51)$ & $12(36)$ & $19(56)$ & $16(70)$ & $5(45)$ & $3(43)$ \\
\hline Cognitive deficits & $54(50)$ & $19(58)$ & $16(47)$ & $11(48)$ & $3(27)$ & $5(71)$ \\
\hline Gait/balance disturbance/dyscoordination & $37(34)$ & $11(33)$ & $10(29)$ & $10(43)$ & $3(27)$ & $3(43)$ \\
\hline Visual deficits & $31(29)$ & $12(36)$ & $10(29)$ & $7(30)$ & $1(9)$ & $1(14)$ \\
\hline Seizure & $15(14)$ & $5(15)$ & $2(6)$ & $6(26)$ & $1(9)$ & $1(14)$ \\
\hline Cranial nerve affection & $16(15)$ & $6(18)$ & $2(6)$ & $4(17)$ & $3(27)$ & $1(14)$ \\
\hline Sensory deficits & $3(3)$ & $2(6)$ & $1(3)$ & 0 & 0 & 0 \\
\hline \multicolumn{7}{|l|}{ Neuroimaging, detection of PML lesions ${ }^{\mathrm{a}}$} \\
\hline Supratentorial & $97(89)$ & $30(91)$ & $31(91)$ & $20(87)$ & $10(91)$ & $6(86)$ \\
\hline Infratentorial & $27(25)$ & $7(21)$ & $10(29)$ & $7(30)$ & $2(18)$ & $1(14)$ \\
\hline Spinal cord & $1(0.9)$ & 0 & 0 & 0 & $1(1)$ & 0 \\
\hline \multicolumn{7}{|l|}{ Lesion distribution } \\
\hline Unilobular & $22(20)$ & $9(27)$ & $5(15)$ & $7(30)$ & 0 & $1(14)$ \\
\hline Multilobular & $81(74)$ & $21(64)$ & $28(82)$ & $16(70)$ & $10(91)$ & $6(86)$ \\
\hline Unknown & $4(4)$ & $2(6)$ & 0 & $1(4)$ & $1(9)$ & 0 \\
\hline Presence of contrast enhancement & $13(12)$ & $2(6)$ & $3(9)$ & $2(9)$ & $3(27)$ & $3(43)$ \\
\hline
\end{tabular}

survivors $(\mathrm{n}=28)$ had a median age of 51 years (IQR 41-63; $p=0.076)$. The median duration from PML onset to death was 4 months (IQR 3-7 months; table 1). Compared with patients with an autoimmune disease $(\mathrm{n}=23)$, those with HIV/AIDS $(\mathrm{n}=33)$ (hazard ratio [HR] 3.26, confidence interval [CI] 1.30-8.16) or a hematologic malignancy $(\mathrm{n}=34)$ (HR 5.04, CI 1.83-13.80) had a shorter survival duration (table 3 ) before and after adjustment in Cox regression models. There was no evidence that the proportional hazards assumption for Cox regression was violated. Pharmacologic attempts to improve PML outcome were observed in 57 patients (53\%), including mirtazapine $(\mathrm{n}=24)$, cytarabine $(\mathrm{n}=19)$, and mefloquine $(\mathrm{n}=14)$.

\section{Discussion}

The low positive predictive value for PML in the present study was unexpected although a significantly lower validity for rare diagnoses in the Swedish NSPR has been recognized in studies with medical record review. ${ }^{16}$ Consistent with the present study, validation of PML diagnoses from a US health insurance population confirmed only $44 / 82$ patients (54\%) as having definite PML. ${ }^{17}$ Another study on patients without HIV reported that 6/24 (25\%) PML diagnoses were confirmed by medical record inspection. ${ }^{18}$ In contrast, data from a Swiss cohort of patients with HIV confirmed 186/226 (82\%) PML diagnoses. ${ }^{19}$ The low prevalence of PML and diagnostic difficulties constitute the main factors explaining the poor diagnosis validity in register data. The large variety of clinical departments suggests limited medical experience and knowledge of PML contributing to a higher risk of misdiagnosis. Furthermore, the consensus statement for PML diagnostic criteria, used in the present study, was only recently established by the American Academy of Neurology neuroinfectious disease section in $2013 .{ }^{15}$ Changes in diagnostic workup procedures are unlikely to have contributed significantly to the poor validity of PML diagnoses, since reliable brain imaging ( $\mathrm{CT}$ or MRI) was performed in the vast majority of the patients. Analysis of JCV in CSF using PCR 
Table 3 Mortality risk in patients with progressive multifocal leukoencephalopathy (PML) with HIV/AIDS and hematologic malignancies, compared with autoimmune diseases

\begin{tabular}{|c|c|c|c|c|c|c|c|}
\hline \multirow[b]{2}{*}{ Model } & \multicolumn{3}{|c|}{ HIVIAIDS } & \multicolumn{4}{|c|}{ Hematologic malignancies } \\
\hline & $p$ Value & HR $(95 \% \mathrm{Cl})$ & $\begin{array}{l}\text { Proportional hazard } \\
\text { assumption ( } p \text { value) }\end{array}$ & $p$ Value & HR $(95 \% \mathrm{Cl})$ & $\begin{array}{l}\text { Proportional hazard } \\
\text { assumption ( } p \text { value) }\end{array}$ & $R^{2}$ \\
\hline Unadjusted & $<0.001$ & $4.01(1.93-8.29)$ & $>0.05$ & $<0.001$ & $3.67(1.78-7.58)$ & $>0.10$ & 0.198 \\
\hline Adjusted for sex and age & $<0.001$ & $4.57(2.12-9.86)$ & $>0.05$ & $<0.01$ & $3.44(1.60-7.39)$ & $>0.10$ & 0.210 \\
\hline $\begin{array}{l}\text { Adjusted for sex, age, } \\
\text { and treatment }^{\mathrm{a}}\end{array}$ & $<0.01$ & $4.86(1.88-12.58)$ & $>0.10$ & $<0.01$ & $3.57(1.49-8.58)$ & $>0.10$ & 0.270 \\
\hline $\begin{array}{l}\text { Adjusted for sex, age, } \\
\text { treatment, and period }\end{array}$ & $<0.01$ & $5.04(1.83-13.80)$ & $>0.05$ & $<0.05$ & $3.26(1.30-8.16)$ & $>0.05$ & 0.296 \\
\hline
\end{tabular}

$\mathrm{Cl}$ = confidence interval; $\mathrm{HR}=$ hazard ratio.

Reference: autoimmune disease.

a Treatment: monoclonal antibodies, cytarabine, mirtazapine or mefloquine, cytarabine, and mirtazapine.

b Period: 1988-1992; 1993-1997; 1998-2002; 2003-2007; 2008-2013.

techniques has been used for routine diagnostic evaluation since the beginning of the 1990s in Sweden and quantitative assays have been used since $2005 .^{20}$ Absence of JCV CSF analyses or negative JCV CSF tests contributed to producing almost half of the probable/possible PML diagnoses. Medical record revision concluded that PML diagnoses were incorrect in a substantial number of patients with progressive supratentorial ischemic or degenerative white matter lesions in immunocompetent individuals. JCV testing in CSF was very rarely performed in the patients with fewer symptoms and signs of PML, potentially indicating an inadequate diagnostic workup.

This study demonstrated a 4-fold increase in PML incidence in 2011-2013 compared with the more stable period, 1988-2010. In addition, there was some evidence of an earlier low magnitude transient increase in incidence between 1990 and 2000 possibly due in part to infection by HIV/AIDS. Swedish HIV surveillance data show that after the arrival of HIV in Sweden, there was a relative stable incidence of new HIV infections before 2002, when the annual incidence started to increase until it peaked in 2006-2007 and has subsequently remained stable or declined slightly. ${ }^{17,21}$ Following the initial increase in numbers with HIV infection among men who had sex with men, this continued to be one of the main routes of transmission during the study period but transmission among heterosexuals was more common among those who engaged in unsafe sex practices while traveling abroad, and to a lesser extent among IV drug users. ${ }^{21}$ HIVrelated mortality was initially high but declined rapidly after introduction of HAART, in 1996 in Sweden, which resulted in a dramatic decrease in mortality. ${ }^{17,22}$ The finding of an unchanged proportion with HIV/AIDS as underlying comorbidity in patients with PML, including pre- and postHAART therapy, was somewhat unpredicted. Approximately one third of the patients with HIV/AIDS received HAART treatment but only 3 of them survived. HIV/AIDS-related mortality in Sweden has remained at a very low and stable level since the first years after HAART introduction, which may have contributed to the absence of a change in HIV/ AIDS-related PML during our study period, ${ }^{17,22}$ and the low number of annual HIV/AIDS diagnoses may also have contributed to the lack of variation in the proportion with HIV/ AIDS among patients with PML over time.

The relatively high number of autoimmune diseases among persons developing PML is in contrast to previous studies. ${ }^{23,24}$ Calabrese and Molloy ${ }^{23}$ described the characteristics of 9,675 patients with PML before the introduction of biological treatments and reported that $0.44 \%$ had a diagnosis of SLE, $0.25 \%$ had RA, and $0.25 \%$ had other connective tissue diseases. In another US study of patients with PML during $2000-2004,2.3 \%$ of the 44 patients had an underlying autoimmune disease. ${ }^{18}$ However, consistent with the present study, a recent review describing drug-associated PML found an underlying autoimmune diagnosis in $58.6 \%$ of the patients. ${ }^{25}$

Almost a quarter (24\%) of all definite/probable/possible PML cases occurred in patients exposed to monoclonal antibody treatments, mainly rituximab or natalizumab, but contemporaneous use of other immunosuppressants was detected in the majority of patients. In Sweden, natalizumab was approved for MS in 2006. Rituximab was approved in 1998 for non-Hodgkin lymphoma, chronic lymphocytic leukemia, RA, and polyangiitis, and is used as an off-label treatment for MS and SLE. PML prevalence in natalizumabtreated patients has been reported to be $>1 / 100$ for patients with MS with additional risk factors and the risk for PML associated with rituximab has been estimated as $1 / 30,000{ }^{13,26}$ Importantly, we detected PML occurrence after only 14 infusions of natalizumab, and absence of previous immunosuppressants, emphasizing the need for effective PML risk stratification. According to a previously published classification system estimating PML risk for specific treatments, we observed exposure to a class 2 risk drug (mycophenolate 
mofetil) and exposure to class 3 risk drugs (azathioprine, cyclophosphamide, fludarabine, methotrexate) before PML among the patients with definite/probable/possible PML. ${ }^{27}$

Presenting symptoms of PML and the presence of multilobular supratentorial localization of PML lesions in the majority of patients are consistent with previous descriptions on clinical characteristics of patients with. ${ }^{28-30}$ One patient presented with a thoracic cord lesion, in addition to supratentorial PML lesions, which is a rare location for PML, although previously detected in a postmortem study. ${ }^{31}$

A potential limitation of this study is the modest number of diagnoses $(n=108)$, which introduces the possibility that a difference in a small number of observations could notably influence the results. However, the study had a very welldefined catchment area: the entire Swedish population during a study period when the registers used to identify all potential PML diagnoses had complete national coverage. Another potential limitation is that a notable increase in PML incidence appeared to occur after 2011: this is a relatively short proportion of our follow-up period, but we chose to treat it separately due to the conspicuous change in temporal pattern. While we were able to eliminate false-positive diagnoses through medical record review, if a PML diagnosis was not recorded correctly in the registers we could not identify it, suggesting our incidence rates may be an underestimate. This concern is mitigated by our use of 2 registers, such that if the diagnosis was not correctly recorded in the Patient Register, it would have likely been identified in the Cause of Death Register, given the high mortality rate of patients with PML. The variable nature of the disease and involvement of multiple clinics to diagnose PML meant that it was difficult to identify the precise date of symptomatic onset in most patients, potentially limiting the accuracy of the survival estimates somewhat.

Given the recent reports on drug-associated PML, it is likely that the increased PML incidence observed in the present study may partly be due to an increased awareness of this diagnosis among physicians prescribing biological agents. ${ }^{25}$ Recent reports of radiologically isolated PML suggest improved monitoring of individuals with higher risk for PML development. ${ }^{32}$ Systematic national recording of diagnoses and associated characteristics may help to identify groups at risk and facilitate the diagnostic process. However, our results demonstrated the difficulty of establishing an accurate PML diagnosis, which despite improved MRI and PCR techniques, remains challenging and emphasizes the importance of urgent contact with a neurology center on suspicion of PML.

\section{Author contributions}

Ellen Iacobaeus: study concept and design, acquisition of data, analysis and interpretation of data, manuscript writing. Sarah Burkill: analysis and interpretation of data, statistical analysis, manuscript writing. Shahram Bahmanyar: study concept and design, interpretation of data, manuscript writing. Ramil Hakim: analysis and interpretation of data, statistical analysis, manuscript writing. Camilla Byström: acquisition of data, analysis and interpretation of data. Mikael Fored: study concept and design. Tomas Olsson: study concept and design, analysis and interpretation of data, manuscript writing. Lou Brundin: study concept and design, analysis and interpretation of data, manuscript writing. Scott Montgomery: obtained funding, study concept and design, analysis and interpretation of data, manuscript writing.

\section{Study funding}

This study was funded predominantly by F. Hoffmann-La Roche Ltd. Additional funding was received from the Stockholm County Council, Swedish Medical Research Council, The Swedish Brain Foundation, and Karolinska Institutet.

\section{Disclosure}

E. Iacobaeus has received unrestricted research grants from Merck and Sanofi-Genzyme. S. Burkill reports no disclosures relevant to the manuscript. S. Bahmanyar has received funding for MS-related research from F. Hoffman-La Roche, Novartis International AG, and AstraZeneca. R. Hakim, C. Byström, and M. Fored report no disclosures relevant to the manuscript. T. Olsson has received unrestricted MS research grants, speaker or advisory board honoraria from Biogen, Novartis, and Genzyme. L. Brundin has received honoraria for advisory boards for Biogen, Sanofi-Genzyme, Novartis, and Teva, and has received lecturing fees from Biogen, Novartis, Teva, and Sanofi-Genzyme. S. Montgomery has received funding for MS-related research from F. Hoffman-La Roche, Novartis International AG, and AstraZeneca, as well as honoraria for serving on an advisory board for IMS Health. Go to Neurology.org/N for full disclosures.

Received June 2, 2017. Accepted in final form October 16, 2017.

\section{References}

1. Berger JR. Progressive multifocal leukoencephalopathy. Curr Neurol Neurosci Rep 2007;7:461-469.

2. De Luca A, Ammassari A, Pezzotti P, et al. Cidofovir in addition to antiretroviral treatment is not effective for AIDS-associated progressive multifocal leukoencephalopathy: a multicohort analysis. AIDS 2008;22:1759-1767.

3. Marzocchetti A, Tompkins T, Clifford DB, et al. Determinants of survival in progressive multifocal leukoencephalopathy. Neurology 2009;73:1551-1558.

4. Jamilloux Y, Kerever S, Ferry T, Broussolle C, Honnorat J, Seve P. Treatment of progressive multifocal leukoencephalopathy with mirtazapine. Clin Drug Invest 2016; 36:783-789.

5. Scarpazza C, Prosperini L, Mancinelli CR, et al. Is maraviroc useful in multiple sclerosis patients with natalizumab-related progressive multifocal leukoencephalopathy? J Neurol Sci 2017;378:233-237.

6. Astrom KE, Mancall EL, Richardson EP Jr. Progressive multifocal leukoencephalopathy; a hitherto unrecognized complication of chronic lymphatic leukaemia and Hodgkin's disease. Brain 1958;81:93-111.

7. d'Arminio Monforte A, Cinque P, Mocroft A, et al. Changing incidence of central nervous system diseases in the EuroSIDA cohort. Ann Neurol 2004;55:320-328.

8. Engsig $\mathrm{FN}$, Hansen $\mathrm{AB}$, Omland $\mathrm{LH}$, et al. Incidence, clinical presentation, and outcome of progressive multifocal leukoencephalopathy in HIV-infected patients during the highly active antiretroviral therapy era: a nationwide cohort study. J Infect Dis 2009;199:77-83.

9. Molloy ES, Calabrese LH. Progressive multifocal leukoencephalopathy: a national estimate of frequency in systemic lupus erythematosus and other rheumatic diseases. Arthritis Rheum 2009;60:3761-3765.

10. Raisch DW, Rafi JA, Chen C, Bennett CL. Detection of cases of progressive multifocal leukoencephalopathy associated with new biologicals and targeted cancer therapies from the FDA's adverse event reporting system. Expert Opin Drug Saf 2016;15:1003-1011. 
11. Molloy ES, Calabrese LH. Progressive multifocal leukoencephalopathy associated with immunosuppressive therapy in rheumatic diseases: evolving role of biologic therapies. Arthritis Rheum 2012;64:3043-3051.

12. Toussirot E, Bereau M. The risk of progressive multifocal leukoencephalopathy under biological agents used in the treatment of chronic inflammatory diseases. Inflamm Allergy Drug Targets 2014;13:121-127.

13. Zaheer F, Berger JR. Treatment-related progressive multifocal leukoencephalopathy: current understanding and future steps. Ther Adv Drug Saf 2012;3:227-239.

14. The National Board of Health and Welfare. Available at: socialstyrelsen.se/english. Accessed April 3, 2017.

15. Berger JR, Aksamit AJ, Clifford DB, et al. PML diagnostic criteria: consensus statement from the AAN neuroinfectious disease section. Neurology 2013;80:1430-1438.

16. Richesson R, Vehik K. Patient registries: utility, validity and inference. Adv Exp Med Biol 2010;686:87-104.

17. European Centre for Disease Prevention and Control/WHO Regional Office for Europe. HIV/AIDS Surveillance in Europe 2015. Stockholm: ECDC; 2016.

18. Eng PM, Turnbull BR, Cook SF, Davidson JE, Kurth T, Seeger JD. Characteristics and antecedents of progressive multifocal leukoencephalopathy in an insured population. Neurology 2006;67:884-886.

19. Khanna N, Elzi L, Mueller NJ, et al. Incidence and outcome of progressive multifocal leukoencephalopathy over 20 years of the Swiss HIV Cohort Study. Clin Infect Dis 2009;48:1459-1466.

20. Bogdanovic G, Brytting M, Cinque P, et al. Nested PCR for detection of BK virus and JC virus DNA. Clin Diagn Virol 1994;2:127-136.

21. Arneborn M, Blaxhult A. Increase of reported HIV infections in Sweden. Euro Surveill 2007;12:E070607.3.

22. Akerlund B, Arneborn M, Berglund T, Giesecke J. Better treatment has reduced AIDS mortality. Increased number of patients with HIV infections will burden the ambulatory care services. Lakartidningen 2002;99:2928-2929.
23. Calabrese LH, Molloy ES. Progressive multifocal leucoencephalopathy in the rheumatic diseases: assessing the risks of biological immunosuppressive therapies. Ann Rheum Dis 2008;67(suppl 3):64-65.

24. Holman RC, Janssen RS, Buehler JW, Zelasky MT, Hooper WC. Epidemiology of progressive multifocal leukoencephalopathy in the United States: analysis of national mortality and AIDS surveillance data. Neurology 1991;41: 1733-1736.

25. Maas RP, Muller-Hansma AH, Esselink RA, et al. Drug-associated progressive multifocal leukoencephalopathy: a clinical, radiological, and cerebrospinal fluid analysis of 326 cases. J Neurol 2016;263:2004-2021.

26. Dong-Si T, Gheuens S, Gangadharan A, et al. Predictors of survival and functional outcomes in natalizumab-associated progressive multifocal leukoencephalopathy. J Neurovirol 2015;21:637-644.

27. Chahin S, Berger JR. A risk classification for immunosuppressive treatment-associated progressive multifocal leukoencephalopathy. J Neurovirol 2015;21:623-631.

28. Steiner I, Berger JR. Update on progressive multifocal leukoencephalopathy. Curr Neurol Neurosci Rep 2012;12:680-686.

29. Sahraian MA, Radue EW, Eshaghi A, Besliu S, Minagar A. Progressive multifocal leukoencephalopathy: a review of the neuroimaging features and differential diagnosis. Eur J Neurol 2012;19:1060-1069.

30. Yousry TA, Pelletier D, Cadavid D, et al. Magnetic resonance imaging pattern in natalizumab-associated progressive multifocal leukoencephalopathy. Ann Neurol 2012;72:779-787.

31. Bernal-Cano F, Joseph JT, Koralnik IJ. Spinal cord lesions of progressive multifocal leukoencephalopathy in an acquired immunodeficiency syndrome patient. J Neurovirol 2007;13:474-476.

32. Hodel J, Darchis C, Outteryck O, et al. Punctate pattern: a promising imaging marker for the diagnosis of natalizumab-associated PML. Neurology 2016;86: 1516-1523. 


\section{The national incidence of PML in Sweden, 1988-2013}

\author{
Ellen lacobaeus, MD, PhD, Sarah Burkill, MSc, Shahram Bahmanyar, MD, PhD, Ramil Hakim, MD, \\ Camilla Byström, Michael Fored, MD, PhD, Tomas Olsson, MD, PhD, Lou Brundin, MD, PhD, \\ and Scott Montgomery, BSc, PhD
}

Cite as: Neurology ${ }^{\circledR}$ 2018;90:e498-e506. doi:10.1212/WNL.0000000000004926

\section{Correspondence}

Dr. lacobaeus

Ellen.lacobaeus@

karolinska.se

\section{Study question}

How has the incidence of progressive multifocal leukoencephalopathy (PML) in Sweden changed between 1988 and 2013?

\section{Summary answer}

The incidence of PML diagnoses in Sweden increased from 1988 to 2013.

\section{What is known and what this article adds}

PML was historically observed in persons with hematologic malignancies, but recent decades have seen reports of PML induced by HIV and treatment with newly introduced targeted immunoregulatory agents. This study provides evidence concerning the incidence of PML within an entire country over 25 years.

\section{Participants and setting}

The study's participants were 250 individuals with a PML diagnosis recorded in the National Swedish Patient Register or the Swedish Cause of Death Register between 1988 and 2013.

\section{Design, size, and duration}

The patients' medical records were obtained from the relevant clinics. A neurologic specialist reviewed these records to extract key demographic and clinical data. For incidence calculations, past data on the Swedish population were obtained from Statistics Sweden.

\section{Primary outcomes}

Each patient was retrospectively classified as having definite, probable, or possible PML or as not having PML based on current diagnostic criteria.

\section{Main results and the role of chance}

PML was confirmed in 108 (43\%) patients, including 84 (34\%) definite, 4 (2\%) probable, and $20(8 \%)$ possible diagnoses. The remaining 142 (57\%) patients had been incorrectly diagnosed. Based on these revised numbers, the Swedish incidence of possible-to-definite PML cases per 100,000 individuals per year increased from 0.026 (95\%

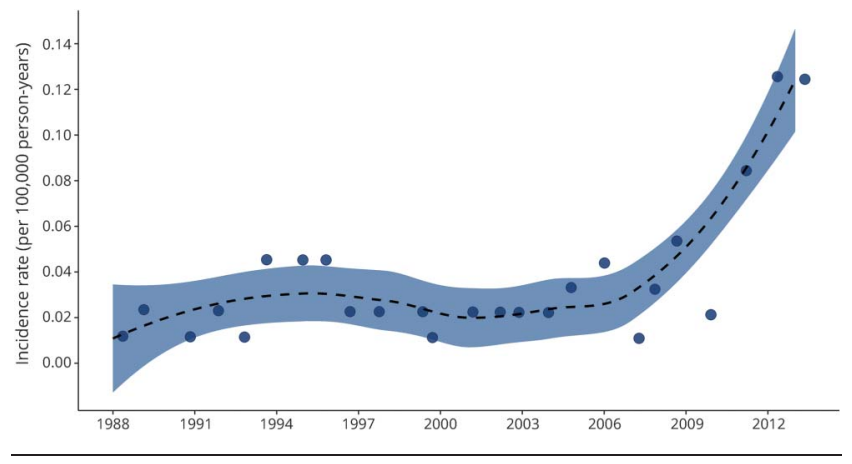

confidence interval [CI] 0.021-0.031) between 1988 and 2010 to 0.11 (95\% CI 0.083-0.137) between 2011 and 2013 $(p<0.001)$. There was a change in the proportions of underlying diseases in PML cases between 1988 and 2013 ( $p<$ 0.001 ), with HIV becoming less common and autoimmune diseases becoming more common.

\section{Bias, confounding, and other reasons for caution}

The study recorded only 108 confirmed PML diagnoses, which may have limited power for some statistical analyses. The nonrecording of PML diagnoses may have caused underestimation of incidence.

\section{Generalizability to other populations}

The study used a well-defined catchment area (i.e., an entire country) with robust recordkeeping, so the results are probably generalizable.

\section{Study funding/potential competing interests}

This study was supported by F. Hoffman-La Roche, the Stockholm County Council, the Swedish Medical Research Council, the Swedish Brain Foundation, and the Karolinska Institute. Some authors report receiving funding, lecture fees, and advisory committee appointments from various pharmaceutical companies. Go to Neurology.org/ $\mathrm{N}$ for full disclosures. 


\section{Neurology}

The national incidence of PML in Sweden, 1988-2013

Ellen Iacobaeus, Sarah Burkill, Shahram Bahmanyar, et al.

Neurology 2018;90;e498-e506 Published Online before print January 10, 2018

DOI 10.1212/WNL.0000000000004926

\section{This information is current as of January 10, 2018}

\section{Updated Information \&} Services

References

Citations

Subspecialty Collections

Permissions \& Licensing

Reprints including high resolution figures, can be found at: http://n.neurology.org/content/90/6/e498.full

This article cites 30 articles, 6 of which you can access for free at: http://n.neurology.org/content/90/6/e498.full\#ref-list-1

This article has been cited by 1 HighWire-hosted articles: http://n.neurology.org/content/90/6/e498.full\#\#otherarticles

This article, along with others on similar topics, appears in the following collection(s):

Incidence studies

http://n.neurology.org/cgi/collection/incidence_studies

Viral infections

http://n.neurology.org/cgi/collection/viral_infections

Information about reproducing this article in parts (figures,tables) or in its entirety can be found online at:

http://www.neurology.org/about/about_the_journal\#permissions

Information about ordering reprints can be found online:

http://n.neurology.org/subscribers/advertise

Neurology ${ }^{\circledR}$ is the official journal of the American Academy of Neurology. Published continuously since 1951, it is now a weekly with 48 issues per year. Copyright @ 2018 The Author(s). Published by Wolters Kluwer Health, Inc. on behalf of the American Academy of Neurology.. All rights reserved. Print ISSN: 0028-3878. Online ISSN: 1526-632X.

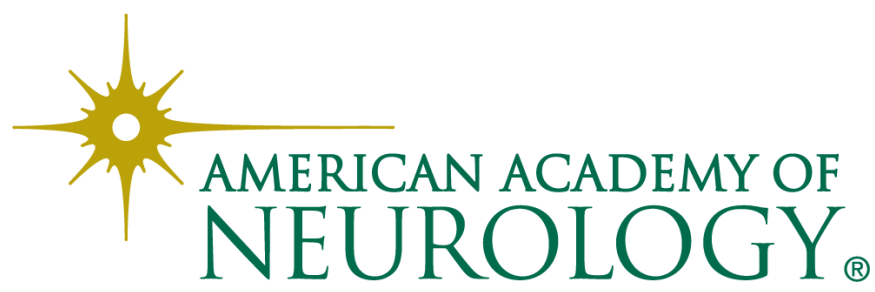

